\title{
(4LS) \\ Inhibition of AA2024-T3 on a Phase-by-Phase Basis Using an Environmentally Benign Inhibitor, Cerium Dibutyl Phosphate
}

\author{
N Birbilis, ${ }^{\mathrm{a}, *, \mathrm{z}}$ R. G. Buchheit, ${ }^{\mathrm{a}, *}$ D. L. Ho, ${ }^{\mathrm{b}}$ and M. Forsyth ${ }^{\mathrm{b}}$ \\ ${ }^{a}$ Fontana Corrosion Center, Department of Materials Science and Engineering, The Ohio State University, \\ Columbus, Ohio 43210, USA \\ ${ }^{b}$ Department of Materials Engineering, Monash University, Victoria 3800, Australia
}

\begin{abstract}
Inhibition of anodic and cathodic reactions on intermetallic compounds in aluminum alloy $2024-\mathrm{T} 3(\mathrm{Al}-4.4 \mathrm{Cu}-1.5 \mathrm{Mg}-0.6 \mathrm{Mn})$ by cerium dibutyl phosphate $\left[\mathrm{Ce}(\mathrm{dbp})_{3}\right]$ additions to dilute chloride solutions was studied using a microelectrochemical cell approach. Cathodic polarization curves were measured on $\mathrm{Al}_{2} \mathrm{Cu}, \mathrm{Al}_{7} \mathrm{Cu}_{2} \mathrm{Fe}, \mathrm{Al}_{20} \mathrm{Cu}_{2} \mathrm{Mn}_{3}$, and $\mathrm{Al}_{3} \mathrm{Fe}$. Results showed the Ce(dbp) 3 effectively inhibits oxygen reduction on each phase. Anodic polarization curves were measured for $\mathrm{Al}_{7} \mathrm{Cu}_{2} \mathrm{Fe}$ and $\mathrm{Al}_{2} \mathrm{CuMg}_{\mathrm{Mg}} \mathrm{com}$ pounds. Results showed that $\mathrm{Ce}(\mathrm{dpb})_{3}$ additions stabilized passivity of these phases. This work suggests that $\mathrm{Ce}(\mathrm{dbp})_{3}$ may effectively inhibit localized corrosion owing to its mixed nature, providing retardation of the oxygen reduction reaction upon noble intermetallics and concomitant retardation of dissolution of phases that may be prone to attack.

(C) 2005 The Electrochemical Society. [DOI: 10.1149/1.2073672] All rights reserved.
\end{abstract}

Manuscript submitted May 23, 2005; revised manuscript received July 22, 2005. Available electronically September $22,2005$.

Localized corrosion of AA2024-T3, which arises due to intermetallic particles, has been intensely investigated over the past decade. ${ }^{1-7}$ Corrosion protection by chromates has been shown to be effective, ${ }^{7-9}$ however in the pursuit of chromate replacements (as hexavalent chromium presents an environmental hazard due to its carcinogenic properties), a vast number of inhibitors have been investigated as possible candidates. Work to date has shown that rareearth compounds possess the characteristics to be viable candidates. ${ }^{10-12}$

From a large scale screening/exposure test program, results have revealed that rare earth-organic compounds can offer significant corrosion protection to AA2024-T3 in chloride solutions. ${ }^{\text {I }}$ Cerium dibutyl phosphate $\left[\mathrm{Ce}(\mathrm{dbp})_{3}\right]$ is a stoichiometric rare earth organic compound composed of $\mathrm{Ce}^{3+}$ and the organophosphate ligand. Typically such rare earth organic compounds have low solubility because they have an extended network structure in the crystalline state as opposed to being discrete cation and anion species typically expected for say, $\mathrm{CeCl}_{3}$ or $\mathrm{Ce}\left(\mathrm{NO}_{3}\right)_{3} \cdot{ }^{13}$ The organophosphate was chosen to be coupled to the $\mathrm{Ce}^{3+}$ in this case since phosphates and phosphonates are known to have inhibitive properties owing to their ability to form insoluble complexes on metal surfaces. ${ }^{14}$ This specific compound has also been shown in EC50 toxicity testing ${ }^{15}$ to be innocuous. The basic screening process (viz. weight loss testing) has shown $\mathrm{Ce}(\mathrm{dbp})_{3}$ to be an excellent inhibitor for AA2024-T3 and potentially a good candidate for an inhibitive pigment in epoxy coatings ${ }^{16}{ }^{16}$ hence demanding the collection of kinetic data regarding inhibitor efficiency.

The complexity of the corrosion evolution for AA2024-T3, however, necessitates the investigation of inhibitor efficiency on a phaseby-phase basis in order to understand the mechanism of inhibitor action. ${ }^{7}$ Previous studies have identified the key intermetallics in AA2024-T3 as $\mathrm{Al}_{2} \mathrm{CuMg}$ (S-phase) ( $\left.>60 \%\right), \mathrm{Al}_{7} \mathrm{Cu}_{2} \mathrm{Fe}$, along with $\mathrm{Al}-\mathrm{Cu}$ and $\mathrm{Al}-\mathrm{Cu}-\mathrm{Fe}-\mathrm{Mn}$-type particles. ${ }^{2,3}$ With the exception of the S-phase, the intermetallic particles are cathodic with respect to the matrix, resulting in archetypal trenching at the particle periphery. The S-phase however, is known to initially be anodic to the matrix, undergoing significant self-dissolution in the form of dealloying, which is now well documented. ${ }^{2,3}$ Dealloying consists of preferential dissolution of $\mathrm{Al}$ and $\mathrm{Mg}$ components of the intermetallic, leaving behind remnants of $\mathrm{Cu}$, allowing the S-phase to ultimately assume the role of a cathodic particle after some critical time. ${ }^{17}$

Chromate is a very efficient inhibitor as a result of both its anodic nature ${ }^{11}$ and also due to its well-documented ability to inhibit

\footnotetext{
* Electrochemical Society Active Member.

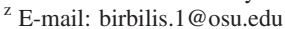

the oxygen reduction reaction. ${ }^{8,9,18}$ Therefore, in this work, we investigated the effectiveness of $\mathrm{Ce}(\mathrm{dbp})_{3}$ as both an anodic and cathodic inhibitor on intermetallic compounds present as particles in 2024-T3, with the aim of characterizing (electrochemically) the mechanism of inhibitor action, while adopting a novel approach to achieve this. Ultimately, the inhibitor must reveal mixed properties to approach the inhibition efficiency of chromates. We suggest that $\mathrm{Ce}(\mathrm{dbp})_{3}$ representing an optimized inhibitor of the Ce-based family, based on chemical considerations, will serve as good environmentally benign corrosion inhibitor for AA2024-T3.

\section{Experimental}

Intermetallic compound crystals ranging from hundreds to thousands of micrometers in diameter were synthesized for electrochemical testing by combining the necessary proportions of constituent pure metals as covered in Ref. 4. Characterization of the intermetallics was done via a scanning electron microscope (SEM, Philips XL-30 FEG-ESEM) enabled with quantitative energy dispersive X-ray spectroscopy (EDXS) and the facility to generate backscattered electron Kikuchi patterns (BEKPs). ${ }^{4}$

Electrochemical testing of the synthesized intermetallic compounds was carried out using an electrochemical microcell method, as reviewed in Ref. 19 and per the methodology in Ref. 4. In this method, the working electrode area is defined by the area of metal which comes into contact with the opening of a microcapillary containing the test with electrolyte/solution. The capillary opening is generally in the vicinity of 20-60 $\mu \mathrm{m}$ diam, dictating that intermetallic particles must be this size or larger to isolate their electrochemical response (which therefore makes isolation of the intermetallics in the bulk alloy not readily possible and justifies the approach herein).

Potentiodynamic polarization was carried out using an Autolab PGSTAT 100 with resolution at low currents. Equilibration time for the working electrode was $5 \mathrm{~min}$ after contact with the solution. Measurements were performed in $0.1 \mathrm{M} \mathrm{NaCl}$ containing $200 \mathrm{ppm}$ $\mathrm{Ce}(\mathrm{dbp})_{3}(\mathrm{pH} 6) . \mathrm{Ce}(\mathrm{dbp})_{3}$ was synthesized by a methathesis reaction as per Ref. 20.

\section{Results and Discussion}

The intermetallic particles of interest in this study were $\mathrm{Al}_{7} \mathrm{Cu}_{2} \mathrm{Fe}, \mathrm{Al}_{3} \mathrm{Fe}, \mathrm{Al}_{2} \mathrm{Cu}, \mathrm{Al}_{20} \mathrm{Cu}_{2} \mathrm{Mn}_{3}$, and $\mathrm{Al}_{2} \mathrm{CuMg}$ (S-phase). With the exception of the S-phase, the above mentioned intermetallics have been identified as functioning as net cathodes 5 in AA2024T3. As a result, the oxygen reduction reaction (ORR) kinetics upon such intermetallics were investigated with and without the presence of $\mathrm{Ce}(\mathrm{dbp})_{3}$. The results of such testing are reported in Fig. 1-4. 


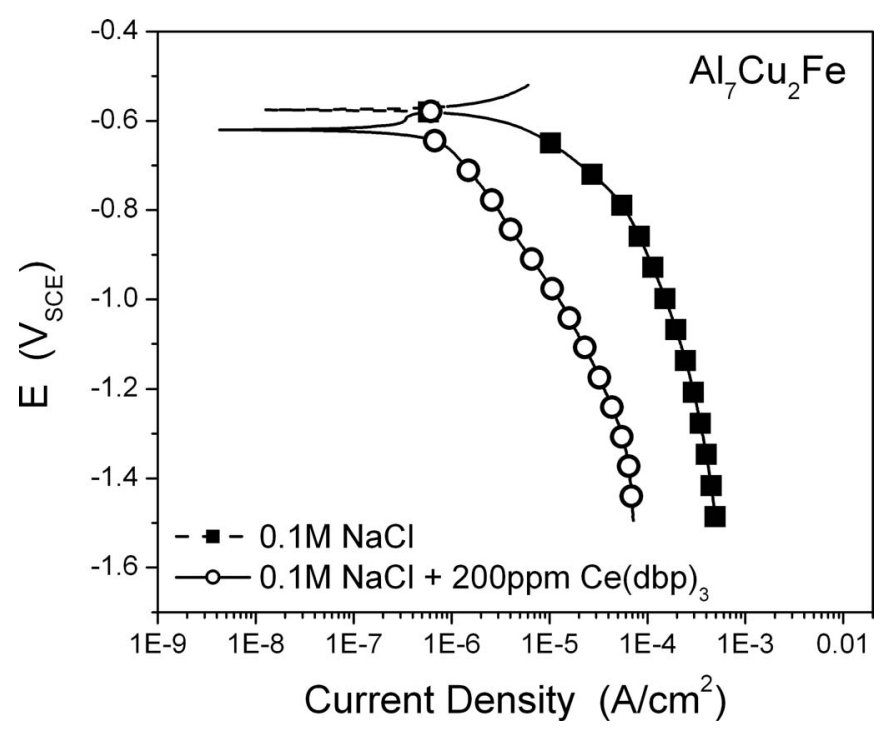

Figure 1. Cathodic polarization $(E-\log i)$ behavior of $\mathrm{Al}_{7} \mathrm{Cu}_{2} \mathrm{Fe}$ in $0.1 \mathrm{M}$ $\mathrm{NaCl}(\mathrm{pH} 6)$ and $0.1 \mathrm{M} \mathrm{NaCl}+200 \mathrm{ppm} \mathrm{Ce}(\mathrm{dbp})_{3}$.

In the case of $\mathrm{Al}_{7} \mathrm{Cu}_{2} \mathrm{Fe}$, we see a reduction in ORR by about an order of magnitude over a range of nearly $1 \mathrm{~V}$. This is a significant finding and lends strong support to the notion that $\mathrm{Ce}(\mathrm{dbp})_{3}$ may function as a cathodic inhibitor suppressing the cathodic reaction upon the metal substrate. Support for this interpretation is also given by the slight decrease apparent in $E_{\text {corr }}$ afforded by the presence of the inhibitor. It is well recognized that a reduction in the rate of cathodic kinetics will undoubtedly translate to a reduction in the corrosion rate of the alloy. This is especially apparent in AA2024T3, whereby the majority of intermetallics (which are chemically and electrochemically different to the matrix) are polarized cathodically at the open-circuit potential (OCP) of the bulk alloy. Typically the OCP of 2024-T3 in quiescent $0.1 \mathrm{M} \mathrm{NaCl}$ is about $-600 \mathrm{mV}_{\mathrm{SCE}}$.

In the case of $\mathrm{Al}_{2} \mathrm{Cu}$, again we see a slight decrease in the $E_{\text {corr }}$ with the presence of the inhibitor, along with a decrease in ORR kinetics with the inhibitor addition. In this case the reduction in ORR kinetics is not as marked as for $\mathrm{Al}_{7} \mathrm{Cu}_{2} \mathrm{Fe}$, however, the decrease in ORR is about fivefold until finally at high cathodic polar-

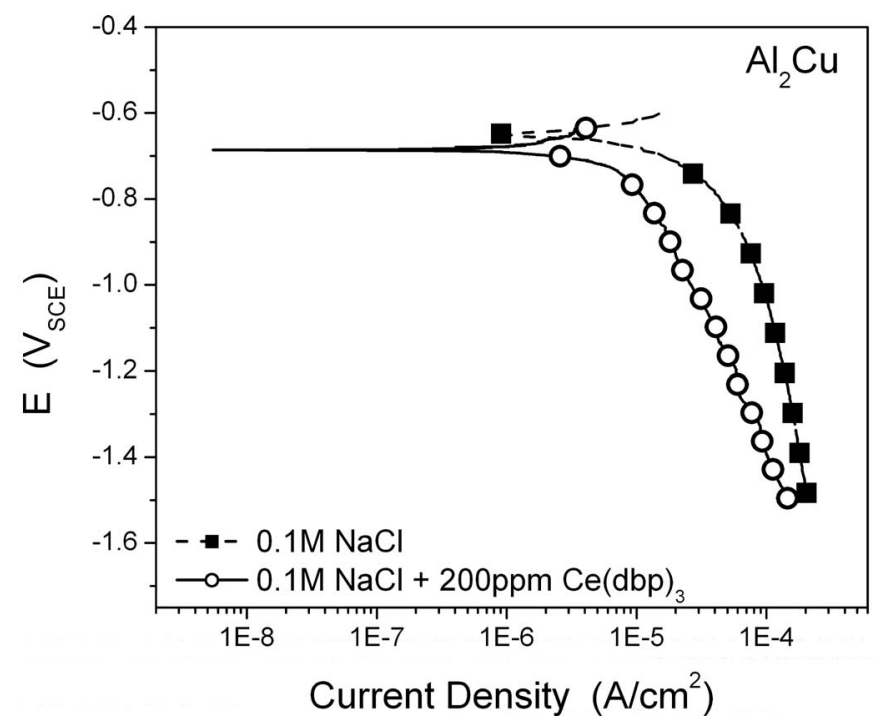

Figure 2. Cathodic polarization $(E-\log i)$ behavior of $\mathrm{Al}_{2} \mathrm{Cu}$ in $0.1 \mathrm{M} \mathrm{NaCl}$ (pH 6) and $0.1 \mathrm{M} \mathrm{NaCl}+200 \mathrm{ppm} \mathrm{Ce}(\mathrm{dbp})_{3}$.

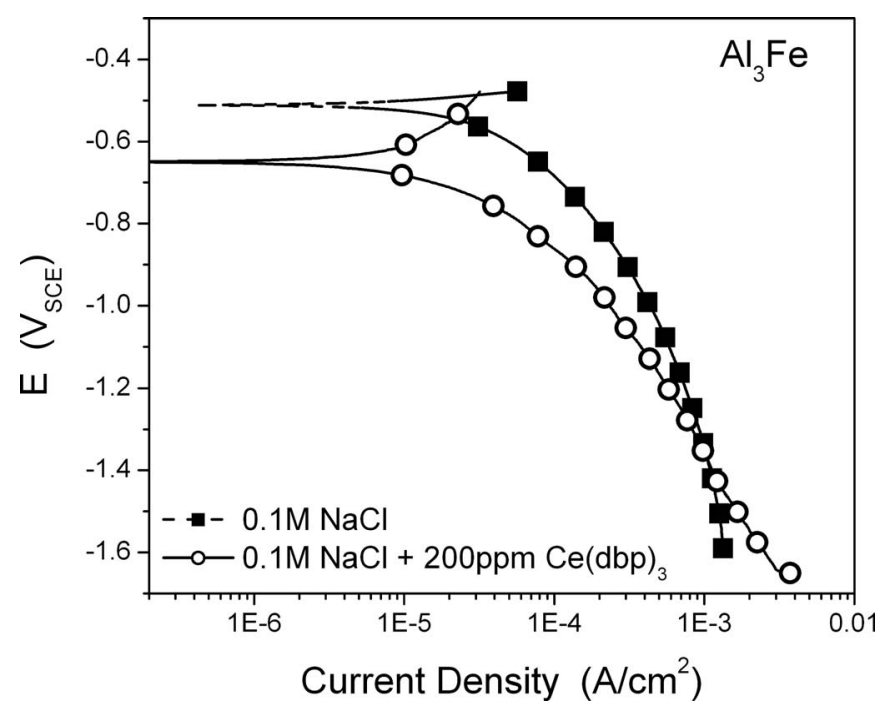

Figure 3. Cathodic polarization $(E-\log i)$ behavior of $\mathrm{Al}_{20} \mathrm{Cu}_{2} \mathrm{Mn}_{3}$ in $0.1 \mathrm{M}$ $\mathrm{NaCl}(\mathrm{pH} \mathrm{6})$ and $0.1 \mathrm{M} \mathrm{NaCl}+200 \mathrm{ppm} \mathrm{Ce}(\mathrm{dbp})_{3}$.

izations only a modest, yet apparent, reduction is observed. Contrary to the results here, Ilevbare and Scully ${ }^{7}$ reported an increase in $E_{\text {corr }}$ with the presence of chromate additions for testing upon $\mathrm{Al}_{2} \mathrm{Cu}$, albeit in somewhat weaker $\mathrm{Cl}$ solutions containing $\mathrm{Na}_{2} \mathrm{SO}_{4}$.

A decrease in $E_{\text {corr }}$ of about $100 \mathrm{mV}$ was observed in the case of the $\mathrm{Al}_{20} \mathrm{Cu}_{2} \mathrm{Mn}_{3}$ intermetallic phase with an inhibitor present. Again, at cathodic potentials in the close vicinity of the $E_{\text {corr }}$, the decrease in ORR kinetics is significant; however the decrease in ORR kinetics is lost at high cathodic polarizations. Although, in the lifetime of the alloy, it is unlikely that potential values as negative as $-1 \mathrm{~V}_{\text {SCE }}$ will ever be realized, it is interesting to note that the apparent level of observed inhibition decreases. However at such negative potential values, cathodic corrosion has likely damaged the sample making comparative analysis rather difficult.

The effect of the inhibitor upon $\mathrm{Al}_{3} \mathrm{Fe}$ is similar to the effect observed upon $\mathrm{Al}_{20} \mathrm{Cu}_{2} \mathrm{Mn}_{3}$. We do note, however, that the ultimate ORR kinetics for this intermetallic (along with $\mathrm{Al}_{7} \mathrm{Cu}_{2} \mathrm{Fe}$ ) are somewhat higher than the others tested (approaching $10^{-3} \mathrm{~A} / \mathrm{cm}^{2}$ ). This effect may possibly be due to enhanced ORR upon Fe, but this was

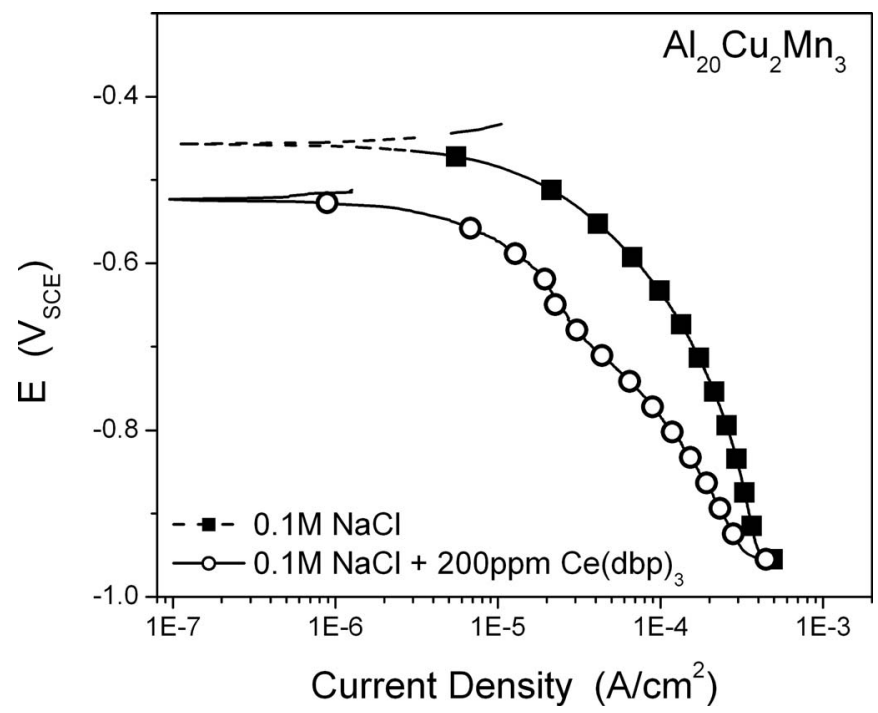

Figure 4. Cathodic polarization $(E-\log i)$ behavior of $\mathrm{Al}_{3} \mathrm{Fe}$ in $0.1 \mathrm{M} \mathrm{NaCl}$ (pH 6) and $0.1 \mathrm{M} \mathrm{NaCl}+200 \mathrm{ppm} \mathrm{Ce}(\mathrm{dbp})_{3}$. 


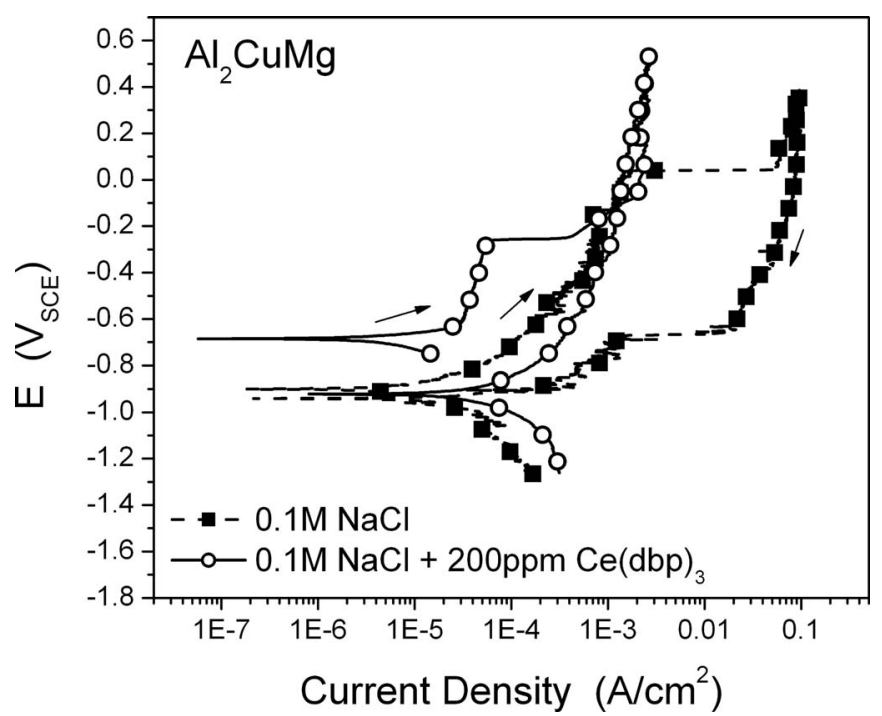

Figure 5. Anodic polarization $\left(E-\log i\right.$ ) behavior of $\mathrm{Al}_{2} \mathrm{CuMg}$ in $0.1 \mathrm{M} \mathrm{NaCl}$ (pH 6) and $0.1 \mathrm{M} \mathrm{NaCl}+200 \mathrm{ppm} \mathrm{Ce}(\mathrm{dbp})_{3}$. Forward and full reverse scan are shown.

not studied here in any detail. Again, a decrease in inhibitor efficiency is seen at high cathodic polarization, suggesting the following possibilities. First, if the ORRs are beginning to become limited by mass-transport, then the inhibited and uninhibited tests will reflect similar values. Second, if the level of inhibition is $\mathrm{pH}$ dependant, the increasingly alkaline environment offered by cathodic polarization may be impacting inhibition efficiency as the local surface $\mathrm{pH}$ tends towards more alkaline values than the bulk solution. It is also possible that in the uninhibited case, the electrode is changing with large cathodic polarization, possibly becoming enriched in $\mathrm{Cu}$ and $\mathrm{Fe}$ with attendant changes in catalytic behavior.

It is clear from these experiments that, in the range of potentials that may be realized for AA2024-T3 in NaCl solutions, the degree of suppression of net cathodic kinetics on all so-called cathodic intermetallic compounds, seems to be significant in the presence of $\mathrm{Ce}(\mathrm{dbp})_{3}$.

The effect of $\mathrm{Ce}(\mathrm{dbp})_{3}$ upon suppression of anodic dissolution is investigated in the case of $\mathrm{S}$ phase (known to undergo active dissolution in the form of dealloying at the open circuit potential of AA2024-T3) and also for $\mathrm{Al}_{7} \mathrm{Cu}_{2} \mathrm{Fe}$, known to significantly populate the bulk alloy as a constituent particle.

The dissolution of the $\mathrm{S}$ phase has received significant attention in the literature owing to operation of the dissolution phenomenon known as dealloying ${ }^{2}$; encompassing selective dissolution of the active components, $\mathrm{Mg}$ and $\mathrm{Al}$, leaving behind $\mathrm{Cu}$-rich particle remnants that ultimately may function as efficient local cathodes. It was recently discussed that chromate was capable of suppressing this dealloying process ${ }^{9}$; in Fig. 5 the effect of $\mathrm{Ce}(\mathrm{dbp})_{3}$ upon anodic dissolution of the $\mathrm{S}$ phase is clearly shown. In this case we observe that the $E_{\text {corr }}$ of the $\mathrm{S}$ phase shifts to increased values in the presence of $\mathrm{Ce}(\mathrm{dbp})_{3}$, possibly revealing an anodic inhibitor characteristic. It appears that $\mathrm{Ce}(\mathrm{dbp})_{3}$ is also capable of reducing anodic kinetics, creating a stable pseudopassive region. Further surface chemistry analysis is required to support whether this is in fact due to suppression of dealloying. We observe almost an order of magnitude difference in the anodic dissolution rate of the $S$ phase up to potentials approaching $-0.25 \mathrm{~V}_{\mathrm{SCE}}$, until inhibitor efficiency is lost and the current density approaches that of the uninhibited test. What is apparent and of greatest significance, however, is that the suppression of dissolution prior to inhibition loss, may subsequently limit the degree of $\mathrm{Cu}$ enrichment and hence possibly the ultimate values of anodic current realized.

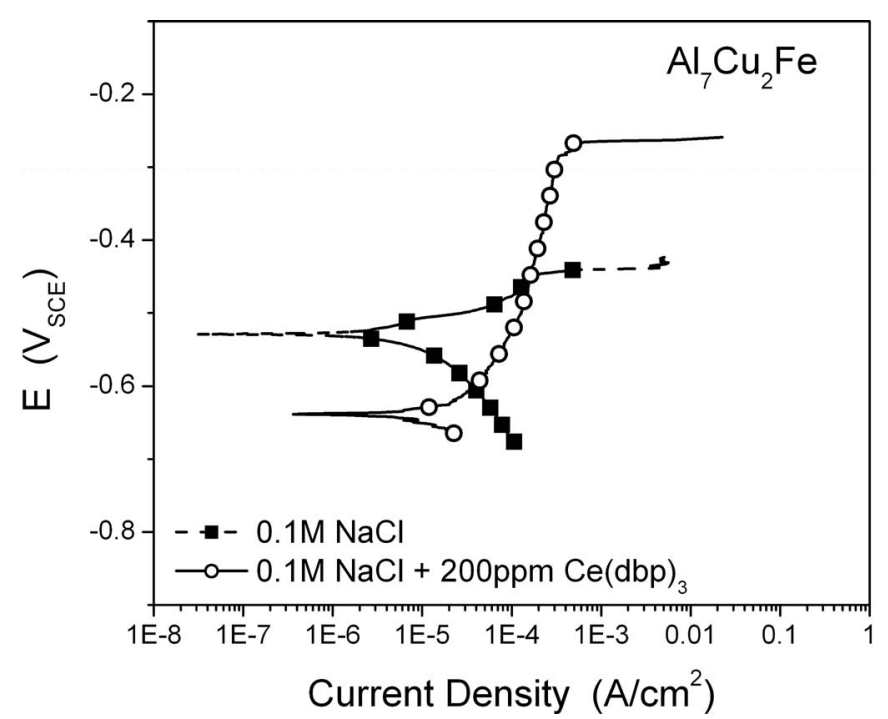

Figure 6. Potentiodynamic polarization $(E-\log i)$ behavior of $\mathrm{Al}_{7} \mathrm{Cu}_{2} \mathrm{Fe}$ in $0.1 \mathrm{M} \mathrm{NaCl}\left(\mathrm{pH}\right.$ 6) and $0.1 \mathrm{M} \mathrm{NaCl}+200 \mathrm{ppm} \mathrm{Ce}(\mathrm{dbp})_{3}$.

In the case of the uninhibited test, there is a high rate of dissolution observed (attributed in such cases to dealloying) prior to the apparent breakdown, which is attributed not to loss of passivity per se (since dealloying has occurred) but to breakdown of an essentially $\mathrm{Cu}$-rich phase. ${ }^{4}$ The ability of $\mathrm{Ce}(\mathrm{dbp})_{3}$ to apparently suppress anodic kinetics is significant, since the ramifications of this upon behavior of the S-phase in bulk 2024-T3 ought to be significant with respect to offering corrosion protection. Thus, if we consider this anodic response in combination with the results shown in Fig. 1-4 which showed the ORR reaction could be significantly suppressed upon cathodic intermetallics, it appears that $\mathrm{Ce}(\mathrm{dbp})_{3}$ may function as a mixed inhibitor.

In regards to the nominally passive $\mathrm{Al}_{7} \mathrm{Cu}_{2} \mathrm{Fe}$ intermetallic, as we previously observed, $E_{\text {corr }}$ is decreased in the presence of $\mathrm{Ce}(\mathrm{dbp})_{3}$, consistent with cathodic inhibition behavior. This suggests that an increase in $E_{\text {corr }}$ with inhibitor additions may only be reserved where active dissolution has called for the anodic component of the inhibitor to be active. Figure 6 shows the potentiodynamic polarization behavior of $\mathrm{Al}_{7} \mathrm{Cu}_{2} \mathrm{Fe}$ in the presence of $\mathrm{Ce}(\mathrm{dbp})_{3}$, revealing an increase in the associated breakdown potential of the intermetallic. Certainly the exact nature of the inhibiting film upon the alloy surface is not yet clear and will be considered in future work. The data here could also be interpreted by considering that $\mathrm{Ce}(\mathrm{dbp})_{3}$ is a more potent cathodic inhibitor than it is anodic; this facilitates the suppression of dealloying but does not necessarily provide the anodic inhibition properties of chromate-based inhibitors. ${ }^{11}$

In terms of overall inhibitor efficiency, it is seen that chromate in solution may perform more dramatically and possibly efficiently with regards to reduction in net reaction rates upon certain intermetallics, based upon results reported in Ref. 8, 9, 11, and 18, however $\mathrm{Ce}(\mathrm{dbp})_{3}$ was capable of mimicking the performance (for the conditions tested here) expected by chromate inhibitors. The positive results from the testing reported herein correspond with immersion/ exposure experiments carried out within our laboratory. ${ }^{12}$ The overall mode of action of this inhibitor may well depend on the surface microstructure and the quantity and distribution of intermetallic sites.

Further work with this inhibitor compound is ongoing and includes the characterization of the inhibiting film, surface chemistry, long-term inhibitor performance, electrochemistry of the bulk alloy, ${ }^{15}$ and testing over a wider $\mathrm{pH}$ window. 


\section{Conclusions}

We have demonstrated the ability of $\mathrm{Ce}(\mathrm{dbp})_{3}$ to specifically inhibit oxygen reduction reactions on the intermetallics identified as being net cathodes in AA2024-T3. Furthermore, we have shown that $\mathrm{Ce}(\mathrm{dbp})_{3}$ can have a significant impact upon the rate of anodic kinetics upon S-phase. These results suggests that this compound may represent a viable avenue as a potential candidate as a chromate replacement inhibitor, at least for near-neutral chloride solutions as tested here, when they can be possibly formulated into a suitable corrosion protection regime.

The Ohio State University assisted in meeting the publication costs of this article.

\section{References}

1. R. G. Buchheit, J. Electrochem. Soc., 142, 3994 (1995).

2. R. G. Buchheit, R. P. Grant, P. F. Hlava, B. McKenzie, and G. L. Zender, J. Electrochem. Soc., 144, 2621 (1997).

3. R. G. Buchheit, L. P. Montes, M. A. Martinez, J. Michael, and P. F. Hlava, J. Electrochem. Soc., 146, 4424 (1999).

4. N. Birbilis and R. G. Buchheit, J. Electrochem. Soc., 152, B140 (2005).

5. G. O. Ilevbare, O. Schneider, R. G. Kelly, and J. R. Scully, J. Electrochem. Soc., 151, B453 (2004).
6. O. Schneider, G. O. Ilevbare, R. G. Kelly, and J. R. Scully, J. Electrochem. Soc., 151, B465 (2004).

7. G. O. Ilevbare and J. R. Scully, Corrosion (Houston), 57, 134 (2001).

8. W. J. Clarke, J. D. Ramsey, R. L. McCreery, and G. S. Frankel, J. Electrochem. Soc., 149, B179 (2002)

9. G. O. Ilevbare and J. R. Scully, J. Electrochem. Soc., 148, B196 (2001).

10. B. R. W. Hinton, D. R. Arnott, and N. E. Ryan, Metals Forum, 7, 211 (1984)

11. M. W. Kendig and R. G. Buchheit, Corrosion (Houston), 59, 379 (2001).

12. D. L. Ho, L. Apateanu, G. B. Deacon, N. Brack, and M. Forsyth, in Proceedings of Corrosion and Prevention Conference 2002, Paper 60, ACA, Adelaide, Australia (2002).

13. T. Behrsing, G. B. Deacon, C. M. Forsyth, M. Forsyth, B. W. Skelton, and A. H. White, Z. Anorg. Allg. Chem., 629, 35 (2003)

14. G. D. Wilcox, D. R. Gabe, and M. E. Warwick, Corros. Rev., 6, 327 (1986); J. W. McCoy, Chemical Treatment of Cooling Water, Chemical Publishing Co., New York (1974).

15. D. L. Ho, B. R. W. Hinton, N. Brack, J. R. Scully, and M. Forsyth, In preparation.

16. D. L. Ho, G. B. Deacon, S. Leary, P. Junk, G. McAdam, B. R. W. Hinton, and M. Forsyth, in Proceedings of Corrosion and Prevention 2003, Paper 81, ACA, Melbourne, Australia (2003)

17. K. Sieradzki and N. Dimitrov, in Proceedings of the Research Topical Symposium Corrosion 2001, p. 293, NACE, Houston, TX (2001).

18. G. S. Frankel and R. L. McCreery, Electrochem. Soc. Interface, 10(4), 34 (2001)

19. M. M. Lohrengal, Corr. Eng. Sci. Technol., 39, 53 (2004).

20. T. Behrsing, Ph.D. Thesis, Chap. 6, School of Chemistry, Monash University, Melbourne, Australia (2003). 